\title{
The Rare Requirement of On-scene Extremity Amputations in the Entrapped Trauma Patient
}

\author{
${ }^{1}$ Gerd D Pust, ${ }^{2}$ Marc M Grossman, ${ }^{3}$ David V Shatz, ${ }^{4}$ Fahim Habib, ${ }^{5}$ Louis Pizano, ${ }^{6}$ Tanya L Zakrison \\ ${ }^{7}$ Antonio Marttos, ${ }^{8}$ Gabriel Ruiz, ${ }^{9}$ Enrique Ginzburg, ${ }^{10}$ Nicholas Namias
}

\begin{abstract}
Objectives: Entrapment of trauma patients in motor vehicle and other accidents is common. Frequently, Emergency Medical Services (EMS) personnel and firefighters are able to free the patient and initiate rapid transport to trauma centers. In rare circumstances, severe torso and extremity injuries combined with major entrapment may require complex rescue operations. These trauma patients spend the "Golden Hour" at the scene under difficult conditions. The objective of this review is to evaluate the role of the trauma surgeon leading the care at the scene of critically injured and entrapped trauma patients with possible need for surgical interventions.
\end{abstract}

Materials and methods: A 10-year review of all trauma surgeon to scene activations between 2005 and 2014 at the Ryder Trauma Center, an urban ACS Level 1 trauma center, was performed. An analysis of the trauma registry, individual cases, and surgical interventions was conducted.

Results: The University of Miami/Jackson Memorial Hospital (UM/JMH) Ryder Trauma Center and Miami Dade Fire Rescue have an established program in place for trauma surgeon to scene activations. During the study period, the on-call trauma surgeon was activated six times and traveled to the scene by air rescue helicopter four times, by ground in 1 case and in 1 case the patient expired before takeoff. One patient required on-scene amputation of an entrapped non-salvageable upper extremity. Two patients required on-scene amputation of bilateral lower mangled, entrapped extremities. One patient required a localized limb preserving surgical procedure to free

${ }^{1,6,8}$ Assistant Professor, ${ }^{2}$ Medical Director, ${ }^{3,5,9}$ Professor ${ }^{4}$ Associate Director, ${ }^{7}$ Associate Professor, ${ }^{10}$ Professor and Chief

1,5-10 Division of Trauma and Surgical Critical Care, The DeWitt Daughtry Family, Department of Surgery, Ryder Trauma Center/Jackson Memorial Hospital, Miller School of Medicine University of Miami, Florida, USA

${ }^{2}$ Department of Emergency Medicine, Jackson Memorial Hospital/Miami-Dade Fire Rescue, Miami, Florida, USA

${ }^{3}$ Division of Trauma and Surgical Critical Care, Department of Surgery, Davis Medical Center, University of California Sacramento, California, USA

${ }^{4}$ Division of Trauma, Department of Surgery, Broward Health Medical Center, Ft Lauderdale, Florida, USA

Corresponding Author: Gerd D Pust, Assistant Professor Division of Trauma and Surgical Critical Care, The DeWitt Daughtry Family, Department of Surgery, Ryder Trauma Center/Jackson Memorial Hospital, Miller School of Medicine University of Miami, Florida, USA, Phone: +13055851180 e-mail: gpust@med.miami.edu him from entrapment. The incidence was $0.016 \%$ of 36,872 trauma alert activated patients evaluated at Ryder Trauma Center during the study period. Hemorrhagic shock, associated injuries, and long scene times were present in all patients. The survival of treated patients was $80 \%$.

Conclusion: The need for on-scene amputations of nonsalvable extremities in entrapped trauma patients is rare. Experienced trauma surgeons should evaluate these patients and decide which interventions are necessary. All efforts should be made to salvage the limb. However, if the entrapped extremity appears nonsalvageable and the patient is in profound life-threatening shock requiring rapid transport, field amputation may be required. Policies, safety training and gear, supply kits, and partnerships with EMS are needed.

Keywords: Amputation, Entrapped, Extremity, Golden Hour, In-field, On-scene, Patient, Trauma.

How to cite this article: Pust GD, Grossman MM, Shatz DV, Habib F, Pizano L, Zakrison TL, Marttos A, Ruiz G, Ginzburg E, Namias N. The Rare Requirement of On-scene Extremity Amputations in the Entrapped Trauma Patient. Panam J Trauma Crit Care Emerg Surg 2016;5(2):93-100.

Source of support: Nil

Conflict of interest: None

\section{INTRODUCTION}

Entrapment of trauma patients in motor vehicle and other accidents is common. In major urban areas, the rate of patient entrapment in motor vehicle accidents is reported between $9.5^{1}$ and $33.3 \% .^{2}$ Dias et $\mathrm{al}^{2}$ showed an overall mortality of $11.7 \%$ in entrapped patients involved in motor vehicle accidents in the urban area of São Paulo, Brazil. Westhoff et $\mathrm{al}^{1}$ showed in a prospective database review of 13,482 motor vehicle collisions in Germany, a mortality of $15.9 \%$ if the trauma patient was entrapped. Furthermore, $74.5 \%$ of all mortalities in entrapped trauma patients occurred in the prehospital phase. ${ }^{1}$ These patients never reach a trauma center in order to receive advanced surgical trauma care. The probability of death at the scene in the study reported by Dias et $\mathrm{al}^{2}$ was 8.2 times greater for entrapped vs nonentrapped patients. Entrapped trauma patients spend "The Golden Hour" of trauma care in the field without advanced care by a trauma surgeon. ${ }^{3}$ Many Emergency Medical Services (EMS) systems in European and Latin American countries promote involvement of emergency physician care at the scene. ${ }^{4}$ In the United States, the "scoop and run" model 
is predominant and favored. The focus of this latter system is the rapid ground or air transport of trauma patients to specialized trauma centers for advanced trauma care. While it works well for penetrating trauma patients with need for rapid surgical interventions and blunt nonentrapped trauma patients, entrapped trauma patients have long scene times and spend "The Golden Hour" of trauma care away from the trauma center. In the vast majority of cases in the United States, the prehospital care is provided by paramedics with no involvement of emergency physicians or trauma surgeons.

Frequently, the EMS personnel and firefighters are able to free the entrapped trauma patient utilizing technical rescue procedures and after prolonged scene time subsequently initiate rapid transport to trauma centers. Sometimes, severe torso and extremity injuries combined with major entrapment may require complex rescue operations. In rare circumstances, technical rescue of an entrapped trauma patient may be impossible and additional surgical intervention may be needed to free the patient. These trauma patients spend the "Golden Hour" at the scene under difficult conditions. During a 10-year period between 2005 and 2014, Miami Dade Fire Rescue requested a trauma surgeon from the county's Level 1 trauma center (UM/JMH Ryder Trauma Center) to the scene six times in order to assist in the rescue of an entrapped trauma patient.

The objective of this review is to evaluate the role of the trauma surgeon leading the care at the scene of critically injured and entrapped trauma patients with possible need for surgical interventions.

\section{MATERIALS AND METHODS}

A retrospective 10-year review of all trauma surgeon to scene activations in Miami-Dade County between 2005 and 2014 at the UM/JMH Ryder Trauma Center was performed. All trauma surgeons with prior scene activations were surveyed regarding patient care and possible surgical interventions on-scene. In addition, a retrospective analysis of our single institution trauma registry for demographic and outcome information was performed. Institutional Review Board approval for retrospective analysis of our trauma registry data was obtained. Demographic data, outcome data, and surgical intervention data were analyzed utilizing Microsoft Excel ${ }^{\mathrm{TM}}$.

\section{RESULTS}

The UM/JMH Ryder Trauma Center and Miami Dade Fire Rescue have an established program in place for trauma surgeon to scene activations. The total number of trauma patients evaluated at Ryder Trauma Center during the study period was 36,872 . The on-call trauma surgeon was activated six times in 10 years. The incidence of trauma surgeon to scene activation was $0.016 \%$. The activated trauma surgeon traveled to the scene by EMS helicopter four times, by ground in 1 case, and in 1 case the patient expired before takeoff. Helicopter pick-up of the trauma surgeon from the trauma center and transport to the scene is the preferred mode of transportation, allowing short activation times and rapid transport of the trauma patient with the trauma surgeon back to the hospital once the patient is extricated. In one case, poor weather conditions with impaired visibility precluded the helicopter from flying. The trauma surgeon was transported by an EMS emergency vehicle, resulting in a prolonged activation to scene time of 50 minutes.

The overall survival rate was $67 \%$. One patient died at the scene prior to arrival of the trauma surgeon. The survival of patients undergoing on-scene treatment by the activated trauma surgeon was $80 \%$. All patients undergoing on-scene treatment by the trauma surgeon, including surgical interventions, survived the prehospital phase. One patient undergoing bilateral lower extremity amputations at the scene subsequently died in the trauma center secondary to severe polytrauma and irreversible shock.

The need for actual surgical procedures at the scene was $80 \%$. Out of five treated patients, one patient required no surgical intervention, one patient required a local surgical procedure to free an impaled lower extremity, one patient required an upper extremity amputation, and two patients required bilateral lower extremity amputations at the scene in order to free patients from entrapment. All patients undergoing on-scene amputation of limbs were examined by attending trauma surgeons with extensive experience in the surgical management of extremities with severe crush injuries. All five extremities requiring on-scene amputation had severe destructive injuries, including major multilevel vascular injuries with loss of circulation to the limb, major injuries to nerve structures, major destructive injuries to muscle and soft tissue, and complex open fractures. Although the reliability of the Mangled Extremity Severity Score (MESS) ${ }^{5}$ is debatable, all patients who underwent amputation at the scene had a MESS score greater than 10. In all cases, the trauma surgeon at the scene assessing the injured extremity judged that even if a technical rescue would be possible, the affected extremity would be nonsalvageable. All patients undergoing surgical intervention at the scene were in prolonged life-threatening class 4 hemorrhagic shock with systolic blood pressures $<80$. All patients undergoing surgical procedures or amputations at the scene had prior extensive failed technical rescue attempts by experienced and state-of-the-art equipped firefighters. Entrapment time with technical rescue attempts prior to surgical 
intervention was between 1 and 11 hours. One patient with an entrapped lower extremity after motor vehicle collision was evaluated by the on-scene trauma surgeon as well as by the EMS medical director. The extremity was deemed viable with a chance of successful salvage and the patient remained hemodynamically stable, allowing a subsequent complex technical rescue from entrapment without the need of surgical intervention.

The review of two sample cases demonstrates the complexity of each specific case and the need for careful evaluation and decision-making process by the on-scene trauma surgeon.

\section{Case 1}

A 17-year-old male passenger was ejected from his passenger seat during a cement truck rollover highway accident. The right upper extremity was crushed and entrapped between the truck and the highway guardrail. Multiple attempts to safely lift up the truck from the entrapped patient utilizing hydraulic systems failed. The on-call trauma surgeon was dispatched and arrived via helicopter at the accident scene. The trauma surgeon evaluated the patient who was found hemodynamically unstable with multiple torso and extremity injuries. Evaluation of the extremity showed major soft tissue and muscle damage, vascular injury with no perfusion of the arm, extensive nerve damage, and multilevel open fractures. It was established by the trauma surgeon that this limb was nonviable and would require subsequent amputation at the hospital. The patient was in critical condition and multiple prior attempts at extrication had failed. Therefore, the trauma surgeon proceeded with on-scene amputation of the upper extremity. Sedation and pain control was achieved utilizing morphine and midazolam. The amputation was completed at the mid upper humerus level at an existing fracture side. The brachial artery had retracted and was not bleeding. Dressings were applied and the patient was rapidly transported to the trauma center by helicopter, where he underwent subsequent operative management with ligation of the brachial artery, irrigation and debridement of the wound, and subsequent reconstruction of a formal amputation stump. The patient survived and was fitted with a limb prosthesis (Fig. 1).
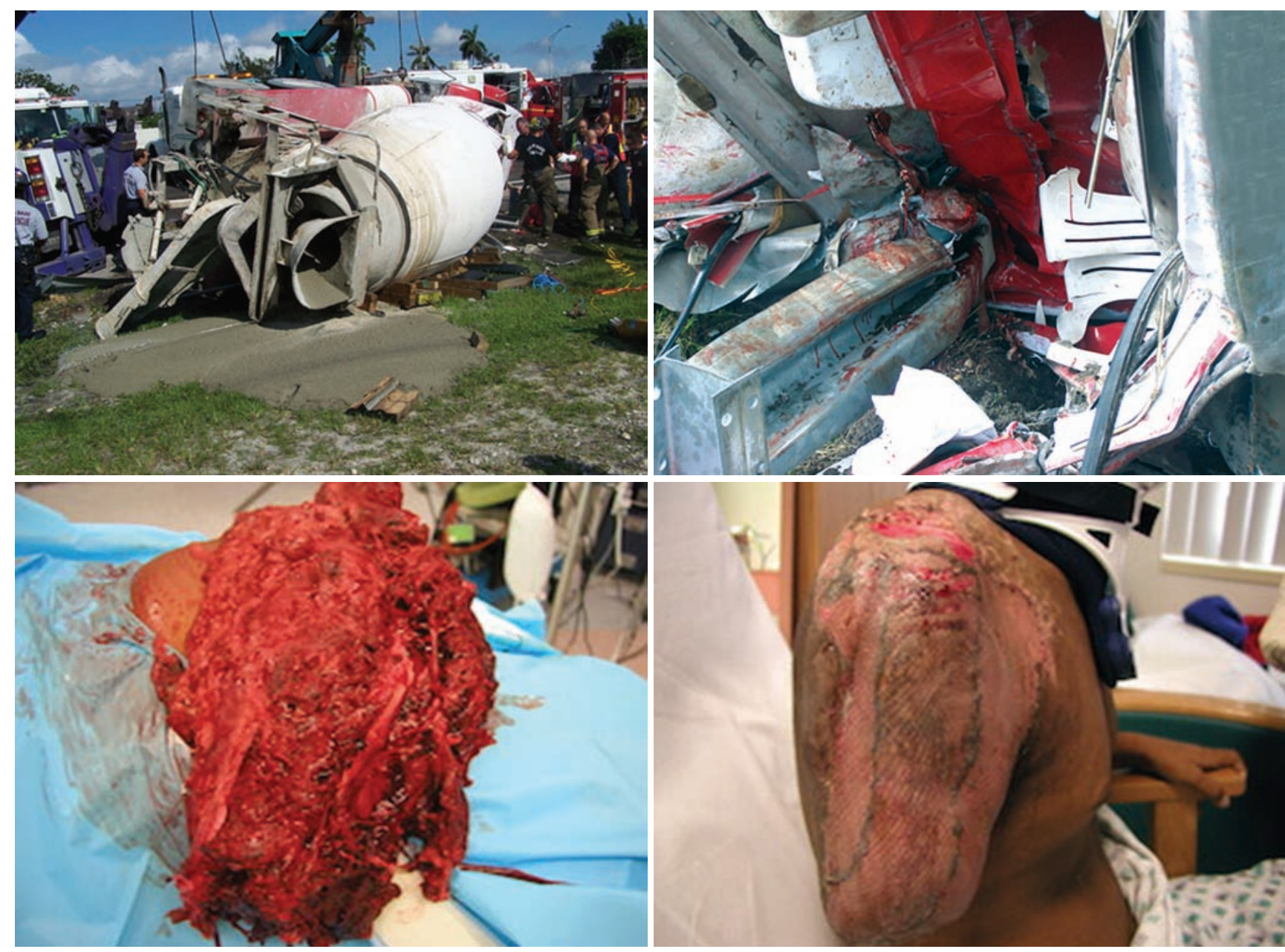

Fig. 1: Crush injury of the right upper extremity with entrapment requiring on-scene amputation 


\section{Case 2}

The patient is a 46-year-old male involved in a high-speed motor vehicle crash with entrapment. Bilateral lower extremities were severely crushed between the engine block and vehicle frame with associated entrapment. Fire rescue teams attempted technical rescue utilizing Jaws of Life hydraulic equipment for $2 \frac{1}{2}$ hours but were unable to free the patient's lower extremities. Despite bilateral lower extremity tourniquet placement, the patient further deteriorated and was in profound hemorrhagic shock with a systolic blood pressure of 70 and heart rate of 146 . Subsequently, the on-call trauma surgeon was requested to the scene for further evaluation and assistance with the rescue efforts. Due to weather conditions with poor visibility the EMS helicopter was grounded and the trauma surgeon was transported from the trauma center to the scene by emergency services rescue vehicle. The trauma surgeon arrived at the scene 2 hours and 40 minutes after the accident. The patient was found in life-threatening profound hemorrhagic shock with active bleeding from bilateral lower extremities and entrapped within the vehicle (Fig. 2). Tourniquets were repositioned in order to control hemorrhage and immediate transfusion of four units $\mathrm{O}$ positive uncrossed packed red blood cells was initiated. The blood products were brought from the trauma center to the scene by the trauma surgeon. Careful assessment of the patient showed severely mangled bilateral lower extremities with multiple open fractures, crushed soft tissue, and muscle and traumatic transection of neurovascular bundles with no circulation to both legs. In fact, the left leg was only attached by a small segment of soleus muscle and skin; all other structures were already separated by the traumatic impact. The right leg had similar severe destruction and both lower extremities were deemed nonsalvage. Due to the absence of space to place hydraulic rescue equipment to separate the entrapping metal parts, technical rescue failed. The patient required laryngeal mask airway (LMA) placement and bag-valve-mask ventilation support and analgesia with morphine. Dividing the remaining soleus muscle and a $2 \mathrm{~cm}$ skin bridge completed the near traumatic amputation of the left leg. The right leg remained severely entrapped and a knee disarticulation was performed. The popliteal artery and veins were clamped with vascular clamps prior to transection and ligated. Both procedures were completed in 8 minutes and the patient was transported to the trauma center by ambulance accompanied by the trauma surgeon. A right subclavian central venous catheter was placed on scene since peripheral access failed. Blood transfusion continued during transport to the trauma center. The operating room team and massive transfusion protocol were activated during transport via cell phone by the trauma surgeon. The patient remained in profound shock with systolic blood pressure between 60 and 70 during transport and on arrival at the trauma center. $\mathrm{He}$ was immediately transferred to the operating room and underwent exploratory laparotomy. Active bleeding from branches of mesenteric vessel was controlled. No solid organ injuries were identified on laparotomy. Bilateral amputation sites were irrigated, debrided, and dressed. On the following day, the patient underwent formal bilateral above knee amputations with closure. The patient remained in the intensive care unit for 11 days. Notable complications included pulmonary embolism and respiratory failure. He subsequently improved and was discharged after 19 days with plans for rehabilitation and prosthesis fitting.

\section{DISCUSSION}

Multiple studies have shown that entrapment of trauma patients after motor vehicle accidents is a common occurrence. The rate of entrapment is between $9.5^{1}$ and $33.3 \%{ }^{2}$ in urban areas. The mortality rates for entrapped trauma patients remain high between $11.7^{2}$ and $15.9 \%{ }^{1}$ The prehospital mortality of entrapped trauma patients after motor vehicle accident remains extremely high with $74.5 \%$ of all deaths occurring prior to trauma center
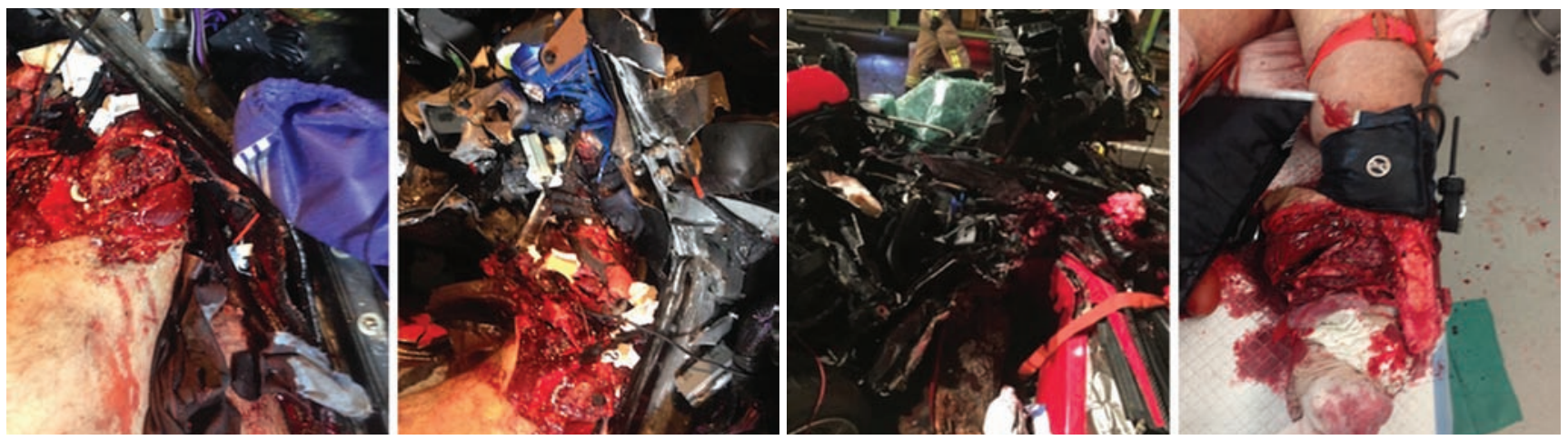

Fig. 2: Severe crush injuries of bilateral lower extremities with complex soft tissue destruction, vascular and nerve injuries with associated complex entrapment. Extensive technical rescue efforts over 2.5 hours were unsuccessful. The patient was in profound life-threating hemorrhagic shock and required subsequent on-scene amputation of bilateral lower extremities at the fracture level 
arrival. ${ }^{1}$ Entrapped trauma patients spend "The Golden Hour" of trauma care in the field without advanced care by a trauma surgeon. ${ }^{3}$ This study shows that only in very rare circumstances is field amputation necessary in order to free patients from entrapment. Over a 10-year period, trauma surgeons were activated to the scene six times and performed five on-scene extremity amputations on four patients. Multiple case reports of successful on-scene extremity amputations in entrapped trauma patients have been reported in the literature. ${ }^{6-10}$ Kampen et $\mathrm{al}^{8}$ surveyed EMS directors from the 200 largest metropolitan areas in North America. Eighteen EMS directors out of 143 surveyed reported a total of 26 in-field extremity amputations in a 5-year period. Motor vehicle accidents were the most common mechanism of trauma requiring in-field amputation. Fifty-three percent of in-field amputations were done by trauma surgeons, and 36.4\% were completed by emergency physicians. Ninety-six percent of the 143 surveyed EMS directors stated that no formal training process for in-field amputations was available. Only two EMS systems in that survey had protocols regarding field amputation in place. Our trauma center and EMS system have a protocol for on-scene amputations in place. Two field-amputation supply boxes with surgical instruments, tourniquets, and required medications are maintained and ready for dispatch at our trauma center.

\section{Proposed Management Plan}

Trauma surgeons and emergency physicians frequently have very limited or no experience working in the field of an accident scene. The call often comes unexpectedly and most physicians have no prior training in prehospital patient care and scene safety. It is of great importance that physicians dispatched to the scene follow instructions and advice from the fire rescue team and paramedics at the scene. Close communication to discuss the situation and the plan of interventions is paramount. Wearing safety gear including fire protective clothing, helmet, and gloves are of great importance. Evaluation of scene safety including surrounding traffic, fire hazards (e.g., leaking fuel), sharp objects like glass and sharp metal edges, risk of collapse, and further entrapment must be carefully assessed. Only after completion of scene safety assessment by fire rescue personnel should medical staff start to evaluate and triage patients. Medical staff must carefully assess the situation to determine if the medical condition demands immediate amputation. The surgeon should not overreact or be overwhelmed by the unfamiliar drama and prematurely decide on surgical amputation procedures. The surgeon should first assess the airway, respiratory status, and circulation and support these systems as indicated. Bleeding should be controlled by direct pressure or tourniquets. Blood transfusion of uncrossed type O blood should be started if the patient is in hemorrhagic shock. If no blood products are available at the scene, the surgeon should request blood products from the nearest hospital to the scene, especially if prolonged entrapment is expected. The surgeon should discuss with the fire rescue team leader and the EMS director technical rescue options, approximate time requirements and medical care. In general, if the patient is stable, spend as much time as needed in order to complete technical rescue of an entrapped extremity. In majority of cases, the entrapped extremity can subsequently be freed from entrapment without the need for amputation. In-field amputations of entrapped extremities should only be performed in trauma patients who are in critical condition, in hemodynamic shock requiring rapid rescue, and have major injuries to the entrapped extremity making subsequent salvage of the extremity after rescue unlikely. Crush injuries with major soft tissue destruction, major injuries to vascular and nerve structures, and associated multilevel open fractures and prolonged absence of circulation to the limb may result in a low limb salvage rate. The MESS score ${ }^{5}$ may be of assistance evaluating the likelihood of limb salvage. In general, trauma surgeons with extensive experience in surgical care for severe extremity injuries should make the decision at the scene if an amputation of a limb is justified or if limb salvage is a reasonable option. However, the data show that trauma surgeons are not always available at the scene and emergency physicians may need to make the assessments of the limb injuries. On-scene amputation of limbs with limited injuries, e.g., closed or open fractures without major destructions of soft tissue, neurovascular structures, and associated entrapment should be avoided. In that scenario, all efforts should be focused on a technical rescue in combination with medical support and pain control. In reality, the decision is often straightforward. Most patients with severe entrapment, hemodynamic shock, and inability of a successful technical rescue have crushed extremities and the assessment of the severity of injuries may show obvious non-salvageability of the limb. The final decision regarding on-scene amputation must be guided by the overall status of the patient, severity of the extremity injury, and likelihood of limb salvage. In the end, the dictum "life before limb" assists in the decisionmaking. Spend enough time to assess the entire situation before finalizing your decision.

We recommend the following steps if an in-field amputation is unavoidable. If the patient is unresponsive, secure the airway with an endotracheal tube or laryngeal mask airway and ventilate. If advanced airways are unavailable or the airway cannot be secured, ventilate the patient with bag-valve-mask ventilation. Obtain venous 
access for transfusion and medication application. Apply a tourniquet if not already in place. The use of ketamine for analgesia and sedation in this setting is preferable since its hemodynamic effects and respiratory depression are minimal. ${ }^{11,12}$ Additional local anesthesia utilizing lidocaine is often helpful, especially when dividing skin and nerve structures. Amputate as distally as possible in order to preserve maximal extremity length for subsequent stump reconstruction. Divide the extremity at the level of a preexisting fracture site if possible or consider disarticulation at a joint in close proximity to the most distal amputation site. Cutting the bone during an in-field amputation is often very difficult secondary to limited space surrounding the entrapped extremity. If the bone needs to be divided, utilize a Gigli saw ${ }^{13}$ which works well in a limited space. Place a hemostat or vascular clamp on major vessels prior to dividing them. Subsequently ligate these structures with 0 silk ties or similar ties. Place a pressure dressing and keep tourniquet up as need to control bleeding.

In summary, entrapped trauma patients have a high risk of mortality secondary to the severity of associated injuries and long prehospital time. ${ }^{1,2}$ Sharp et $\mathrm{al}^{7}$ promote the establishment of "field amputation teams" in major metropolitan areas in order to be ready for these difficult cases. The authors of this manuscript recommend the creation of "Entrapped Trauma Patient Response Teams ERTs" consisting of a trauma surgeon, the EMS medical director, EMS chief, and a senior paramedic. The focus of the ERT should be stabilizing the entrapped patient at the scene, control of hemorrhage, resuscitation of entrapped patients in hemorrhagic shock with blood products at the scene, provision advanced airway and ventilation support as indicated, and administration of sufficient pain control, which often facilitates technical rescue. In very rare circumstances, ERTs may have to perform surgical procedures, including amputations, at the scene. Physicians in Europe and Latin America are routinely involved in the on-scene and prehospital care of trauma patients. Introduction of ERTs may be a first step to explore and study the feasibility of trauma surgeon involvement in on-scene and prehospital care of trauma patients in the United States.

\section{REFERENCES}

1. Westhoff J, Haasper C, Otte D, Probst C, Krettek C, Richter M. Motor vehicle accidents with entrapment. A medical and technical investigation of crash mechanism, injury pattern and severity of entrapment of motor vehicle occupants between 1983 and 2003. Chirurg 2007 Mar;78(3):246-253.

2. Dias AR, de Campos Vieira Abib S, Poli-de-Figueiredo LF, Perfeito JAJ. Entrapped victims in motor vehicle collisions: characteristics and prehospital care in the city of Sao Paulo, Brazil. Clinics (Sao Paulo) 2011;66(1):21-25.

3. Cowley RA. A total emergency medical system for the State of Maryland. Md State Med J 1975 Jul;24(7):37-45.

4. Sturm JA, Pape HC, Dienstknecht T. Trauma care in Germany: an inclusive system. Clin Orthop Relat Res 2013 Sep;471(9): 2912-2923.

5. Johansen K, Daines M, Howey T, Helfet D, Hansen ST Jr. Objective criteria accurately predict amputation following lower extremity trauma. J Trauma 1990 May;30(5):568-572; discussion 572-573.

6. Stewart RD, Young JC, Kenney DA, Hirschberg JM. Field surgical intervention: an unusual case. JTrauma 1979 Oct;19(10): 780-783.

7. Sharp CF, Mangram AJ, Lorenzo M, Dunn EL. A major metropolitan "field amputation" team: a call to arms ... and legs. J Trauma 2009 Dec;67(6):1158-1161.

8. Kampen KE, Krohmer JR, Jones JS, Dougherty JM, Bonness RK. In-field extremity amputation: prevalence and protocols in emergency medical services. Prehosp Disaster Med 1996 Jan-Mar;11(1):63-66.

9. Ebraheim NA, Elgafy H. Bilateral below-knee amputation surgery at the scene: case report. J Trauma 2000 Oct;49(4): 758-759.

10. Foil MB, Cunningham PR, Hale JC, Benson NH, Treurniet S. Civilian field surgery in the rural trauma setting: a proposal for providing optimal care. J Natl Med Assoc 1992 Sep;84(9): 787-789.

11. Petz LN, Tyner S, Barnard E, Ervin A, Mora A, Clifford J, Fowler M, Bebarta VS. Prehospital and en route analgesic use in the combat setting: a prospectively designed, multicenter, observational study. Mil Med 2015 Mar;180(Suppl 3): 14-18.

12. Tran KP, Nguyen $Q$, Truong XN, Le V, Le VP, Mai N, Husum H, Losvik OK. A comparison of ketamine and morphine analgesia in prehospital trauma care: a cluster randomized clinical trial in rural Quang Tri province, Vietnam. Prehosp Emerg Care 2014 Apr-Jun;18(2):257-264.

13. Brunori A, Bruni P, Greco R, Giuffré R, Chiappetta F. Celebrating the centennial (1894-1994): Leonardo Gigli and his wire saw. J Neurosurg1995 Jun;82(6):1086-1090. 


\section{El requisito raro de amputaciones de extremidades en escena en el paciente de trauma atrapado}

Los autores que trabajan en un reconocido centro de trauma Americano reportan sobre la activación de trauma del cirujano a la escena para tratar a los pacientes atrapados. El centro de Trauma de Ryder tiene una larga historia de excelencia y este informe se suma a la reputación. Es muy importante recordar que todos los profesores en su centro son cirujanos muy experimentados y altamente calificados. Las decisiones que se describen en este manuscrito requieren el máximo nivel de juicio clínico. Las decisiones deben ser tomadas en tiempo real, sin necesidad de pruebas de diagnóstico y no son reversibles. Una vez que se ha producido una amputación en campo, no se puede revertir. Incluso en este centro muy ocupado, es necesaria esta terapia muy raramente, en $0.016 \%$ de los pacientes tratados. No hay grupo de control aquí. Es imposible saber cómo la gente les ha ido con la atención estándar, pero las cifras son impresionantes. Su supervivencia del $67 \%$ es impresionante y fue del $80 \%$ en aquellos que sobrevivieron al ingreso en el hospital. Los autores deben ser felicitados.

En el centro del trauma de Shock, tenemos un programa similar, el equipo Go. Se trata de un equipo multidisciplinario, integrado por un cirujano, por lo general un cirujano ortopédico, un anestesista y enfermeras. Ellos viajan con medicamentos, sangre, equipos y líquidos por vía intravenosa, llevando con ellos todo lo necesario para brindar atención al campo para estos pacientes enfermos graves. Sin embargo, mientras que el equipo Go es activado varias veces al mes, a menudo la liberación del paciente es lograda mientras el equipo es desplegado. Yo diría que esto también sucede en Miami. Después de todo, puede ser difícil saber si la extricación será un éxito y cuánto tiempo va a tomar. Si los proveedores pre-hospitalarios esperan demasiado tiempo para activar este recurso, los pacientes pueden morir en espera de su llegada.

También es importante destacar el compromiso necesario para proporcionar este recurso. La formación especializada es necesaria para proporcionar este servicio. Un principio central de la respuesta a los desastres es no tener buenas intenciones, pero la gente no entrenada de responder. A menudo obstaculizan los esfuerzos de rescate y pueden llegar a sufrir daños a sí mismos, lo que agrava el problema. Nuestros proveedores deben completar un curso de formación rigurosa y deben estar muy familiarizado con la estructura de mando en la escena de rescate, así como la necesidad absoluta de equipos de protección y medidas de seguridad para garantizar la mejor atención. Nuestro equipo entrena varias veces al año para permanecer al tanto.

Recursos institucionales deben estar disponibles inmediatamente, 24 horas al día, 7 días a la semana. Vehículos de transporte, ya sean aéreas o terrestres deben estar preparados. También deben estar disponibles personal calificado. Esto puede no ser un problema durante la jornada de trabajo normal. Muchas de estas llamadas vienen en las noches y/o fines de semana. En ese caso, solo el cirujano inmediatamente disponible será el único que probablemente este de llamada. Sin embargo, enviando el cirujano de guardia o un anestesista que está programado para proporcionar atención deja un agujero en el centro de trauma que debe ser llenado rápidamente.

Advanced field care is not needed very often but when needed, nothing else will suffice. This is not something that can be manufactured on the fly. All issues must have been considered early. The system must be in place. The team at the Ryder Trauma Center has shown us that it is possible to do it and do it well. We owe them a debt of gratitude.

Cuidado en el campo avanzada no se necesita muy a menudo, pero cuando es necesario, nada más es suficiente. Esto no es algo que puede ser fabricado sobre la marcha. Todos los asuntos deben haber sido considerados tempranamente. El sistema debe estar en su lugar. El equipo del Centro de Trauma de Ryder nos ha demostrado que es posible hacerlo y hacerlo bien. Les debemos una deuda de gratitud.

Thomas Scalea

Profesor de Cirugía Jefe de Cirugía

University of Maryland Medical Center

R Adams Cowley Shock Trauma Center Baltimore, Maryland, EE.UU.

\section{The Rare Requirement of Scene Extremity Amputations in the Entrapped Trauma Patient}

The authors who work at an extremely well-known American trauma center report on trauma surgeon activation to the scene to treat entrapped patients. The Ryder Trauma Center has a long history of excellence and this report 
adds to that reputation. It is extremely important to remember that all faculty at their center are very experienced and highly skilled surgeons. The decisions described in this manuscript require the highest level of clinical judgment. The decisions must be made in real time, without diagnostic testing and are not reversible. Once a field amputation has occurred, one cannot reverse it. Even in this extremely busy center, this therapy is needed very rarely, in $0.016 \%$ of patients treated. There is no control group here. It is impossible to know how people would have fared with standard care but the figures are impressive. Their survival of $67 \%$ is impressive and was $80 \%$ in those who survived to hospital admission. The authors should be congratulated.

At the Shock Trauma Center, we have a similar program, the Go Team. This is a multidisciplinary team comprising a surgeon, usually an orthopedic surgeon, an anesthesia provider, and nurses. They travel with medications, blood, equipment, and IV fluids, bringing everything needed to provide field care to these desperately ill patients. However, while the Go Team is activated several times per month, often extrication is accomplished as the team is deployed. I would guess this also happens in Miami. After all, it may be difficult to know whether extrication will be successful and how long it will take. If prehospital providers wait too long to activate this resource, patients may die waiting for their arrival.

It is also important to underscore the commitment necessary to provide this resource. Specialized training is necessary to provide this service. A central principle of disaster response is to not have well meaning but untrained people responding. They often impede rescue efforts and may become injured themselves, compounding the problem. Our Go Team providers must complete a rigorous training course and must be very familiar with the command structure at the rescue scene as well as the absolute need for protective gear and safety measures to ensure the best care. Our team trains several times per year to remain facile.

Institutional resources must be immediately available, 24 hours per day, 7 days per week. Transportation vehicles, whether air or ground assets, must be ready. Qualified personnel must also be available. This may not be an issue during the normal work day. Many of these calls come in nights and/or weekends. In that case, the only immediately available surgeon will likely be the one on call. However, dispatching the surgeon on call or an anesthesia provider who is scheduled to provide care leaves a hole at the trauma center which must be filled quickly.

Advanced field care is not needed very often but when needed, nothing else will suffice. This is not something that can be manufactured on-the-fly. All issues must have been considered early. The system must be in place. The team at the Ryder Trauma Center has shown us that it is possible to do it and do it well. We owe them a debt of gratitude.

Thomas Scalea

Surgeon-in-Chief, Professor, Department of Surgery Maryland Institute of Medical Sciences, R Adam Cowley Shock Trauma Center Baltimore, Maryland, USA 